\title{
Comparison of Detection Methods based on Computer Vision and Machine Learning
}

\author{
Wenjuan Jia ${ }^{1,2, a, ~ *}$, Yongyan Jiang ${ }^{3, b}$ \\ ${ }^{1}$ School of Computer Science and Technology, Nanjing Normal University, China \\ ${ }^{2}$ Jiangsu Key Laboratory of 3D Printing Equipment and Manufacturing, Nanjing, Jiangsu, China \\ ${ }^{3}$ College of Science, Zhongyuan University of Technology, Zhengzhou, 450007, China \\ a1286741985@qq.com, bjiangyongyan@126.com
}

Keywords: Pathological image detection; Automatic diagnosis system; Feature extraction.

\begin{abstract}
Invisible diseases inside human's body even will lead the end of life. Hence, scientists put forward many computer-aided methods to detect the abnormalities in the body, which are proved to be beneficial for both doctors and patients. Nevertheless, how to select an accurate and convenient approach is a disturbing problem. In this paper, we will introduce some effective methods of image classification, and focus on the strength and weakness of them. Finally, we will present our future work on pathological image detection.
\end{abstract}

\section{Introduction}

Diseases inside the body are nearly invisible in the early stage, such as Alzheimer's disease [1-3], abnormal breast disease, multiple sclerosis [4, 5], microbleed [6], unilateral hearing loss [7], etc., so we must use other tools to find and treat it. Computer-aided methods, used to develop automatic diagnosis system, have been proved to be remarkable [8]. Different researchers proposed different methods to detect these diseases $[9,10]$.

Magnetic resonance imaging (MRI), as an imaging technique, can generates high quality images of the anatomical structures of the human body, especially in the brain. When detecting pathological brain, Yang (2017) [11] proposed a method via Hu moment invariants and machine learning. For abnormal breast, Grimm (2016) [12] introduced digital breast tomosynthesis (DBT), this method is a more innovative imaging technique, which reduces breast tissue superposition, in comparison to mammography. Imaging features and the diagnosis of tuberculosis of the breast can be learned from [13]. Hearing loss in children have been underestimate, but the effect on development and the potential pathophysiologic mechanism are now being noticed [14]. This paper tries to give a comparison of contemporary methods.

\section{Methods and results}

Chen (2017) [15] introduced the method of linear regression classifier, which is used to detect a feature-free 30-disease pathological brain. The accuracy of this method arrived at $97.51 \%$.

Sun (2016) [16] put forward the method of extracting 12 fractional Fourier entropy (FRFE) features, then transporting those extracted features to an improved multi-layer perceptron (MLP) classifier. The average accuracy of the proposed method is $99.53 \%$.

Lu (2016) [17] presented a novel pathological brain detection approach, which employed 2D discrete wavelet transform (DWT), and calculated the entropy as features. Then the pathological or healthy images are classified on radial basis function neural network (RBFNN). This method achieved a global accuracy of $95.44 \%$.

Atangana (2016) [18] put forward an innovative method, stationary wavelet entropy (SWE), to extract features from image. The accuracy of the detected pathological brain images is $100 \%$. 
Zhou (2016) [19] selected wavelet entropy as features, a feed-forward neural network (FNN) as classifier to diagnosis the pathological or healthy brain image. The result of 64 images show that the average accuracy reached $100.00 \%$.

Chen (2017) [20] combined wavelet packet Tsallis entropy (WPTE), feedforward neural network (FNN), and real-coded biogeography-based optimization (RCBBO) for pathological brain detection.

Under the background of existing methods for detection of Alzheimer's disease (AD), Wang (2016) [21] devoted to develop a better innovative system for computer-assisted AD detection, which based on following components: wavelet entropy, multilayer perceptron, and biogeography-base optimization. Moreover, this approach got an accuracy of $92.40 \pm 0.83 \%$. Atem (2017) [22] suggested that we can apply the linear regression with a randomly censored covariate to an Alzheimer's study.

Apart from pathological brain disease, breast cancer cannot diagnosis without any other tools. Nevertheless, we can detect the abnormalities of the breast before it become cancer with computer vision method. Chen (2016) [23] designed a program on account of wavelet energy entropy (WEE) and linear regression classifier (LRC) with 10-fold stratified cross validation.

In abnormal breast detection, Rao (2017) [24] also suggested a novel method. After segmenting the region-of-interest, the authors employed the weighted-type fractional Fourier transform (WFRFT) to get the unified time-frequency spectrum. Then author mentioned principal component analysis (PCA) for spectrum reduction. Next, feed-forward neural network (FNN) was used to generate the classifier, and Jaya was utilized to train the classifier.

Besides the diseases mentioned above, computer vision can analyze the etiology of hearing loss, which is helpful for us to prevent or cure it. In view of fractional Fourier transform (FRFT), Li (2016) [25] developed an approach to detect hearing loss which was proved to be efficient and accurate. The single-hidden-layer feed-forward neural network (SFN) classifier was trained by the Levenberg-Marquardt algorithm, and the accuracies are all higher than $95 \%$.

From Table 1 to

Table 3, we can learn the shortcomings of different methods. Hence, we can select suitable method in our experiment.

Table 1. Comparison of efficacy involved images in abnormal breast detection

\begin{tabular}{|c|c|c|c|}
\hline Authors & Method & Accuracy & Weakness \\
\hline $\begin{array}{c}\text { Chen } \\
(2016)\end{array}$ & $\begin{array}{c}\text { Wavelet energy entropy (WEE) + linear } \\
\text { regression classifier (LRC) }\end{array}$ & $\begin{array}{c}\text { Accuracy of } 91.85 \pm \\
2.21 \%, \text { sensitivity of } \\
92.00 \pm 3.20 \%, \text { specificity } \\
\text { of } 91.70 \pm 3.27 \%\end{array}$ & $\begin{array}{c}\text { The e tissues only } \\
\text { include three types }\end{array}$ \\
\hline Rao & The weighted-type fractional Fourier & Accuracy of $92.27 \pm$ & The system is not \\
(2017) & $\begin{array}{c}\text { transform (WFRFT) + principal component } \\
\text { analysis (PCA) + feed-forward neural }\end{array}$ & $\begin{array}{c}3.49 \%, \text { sensitivity of } \\
\text { rebust enough to } \\
\text { detect abnormal } \\
\text { breast }\end{array}$ \\
\hline
\end{tabular}

Table 2. Comparison of efficacy involved images in hearing loss detection

\begin{tabular}{|c|c|c|c|}
\hline Authors & Method & Accuracy & Weakness \\
\hline $\begin{array}{c}\text { Li (2016) } \\
{[25]}\end{array}$ & $\begin{array}{c}\text { The fractional Fourier transform (FRFT) - } \\
\text { principal component analysis (PCA) - } \\
\text { single-hidden-layer feed-forward neural network } \\
\text { (SFN) - Levenberg-Marquardt (LM) }\end{array}$ & Higher than 95\% & $\begin{array}{c}\text { This method has } \\
\text { lower accuracy on } \\
\text { overall population }\end{array}$ \\
\hline $\begin{array}{c}\text { Nayak } \\
(2017) \\
{[26]}\end{array}$ & $\begin{array}{c}\text { Stationary wavelet entropy (SWE) + single-hidden } \\
\text { layer feedforward neural network (SLFNN) }\end{array}$ & $\begin{array}{c}\text { Accuracies of HC, } \\
\text { LHL and RHL are } \\
96.94 \%, 97.14 \% \text { and } \\
97.35 \%\end{array}$ & $\begin{array}{c}\text { It takes about four } \\
\text { minutes to train the } \\
\text { network. }\end{array}$ \\
\hline $\begin{array}{c}\text { Gorriz } \\
(2016) \\
{[27]}\end{array}$ & $\begin{array}{c}\text { Wavelet entropy (WE) +directed acyclic graph } \\
\text { support vector machine (DAG-SVM) }\end{array}$ & $95.10 \%$ & $\begin{array}{c}\text { Cannot implicated } \\
\text { the related brain } \\
\text { area }\end{array}$ \\
\hline
\end{tabular}


Table 3. Comparison of efficacy involved images in pathological brain detection

\begin{tabular}{|c|c|c|c|}
\hline Authors & Method & Accuracy & Weakness \\
\hline $\begin{array}{l}\text { Chen } \\
(2017) \\
{[15]}\end{array}$ & Linear Regression Classifier(LRC) & $\begin{array}{l}\text { Accuracy }=97.51 \%, \\
\text { sensitivity }=96.71 \%, \\
\text { specificity }=97.73 \%\end{array}$ & $\begin{array}{l}\text { Only } 117 \text { were } \\
\text { classified correctly } \\
\text { in } 200 \text { brains }\end{array}$ \\
\hline $\begin{array}{l}\text { Sun } \\
(2016) \\
{[16]}\end{array}$ & $\begin{array}{c}\text { Fractional Fourier entropy (FRFE) } \\
\text { +multi-layer perception improved by Kappa } \\
\text { coefficient (KC-MLP) +adaptive real-coded } \\
\text { biogeography-based optimization } \\
\text { (ARCBBO) }\end{array}$ & $99.53 \%$ & $\begin{array}{l}\text { Dataset only } \\
\text { contains } 66 \text { brain } \\
\text { images }\end{array}$ \\
\hline $\begin{array}{l}\text { Lu (2016) } \\
\quad[17]\end{array}$ & $\begin{array}{c}\text { Wavelet entropy (WE) + radial basis function } \\
\text { neural network (RBFNN) }\end{array}$ & $\begin{array}{l}\text { Accuracy of } \\
95.44 \%, \text { sensitivity } \\
\text { of } 95.89 \% \\
\text { specificity of } \\
92.78 \% \\
\end{array}$ & $\begin{array}{l}\text { The dataset was } \\
\text { small. This method } \\
\text { cannot classify } \\
\text { different types }\end{array}$ \\
\hline $\begin{array}{l}\text { Atangana } \\
(2016) \\
{[18]}\end{array}$ & $\begin{array}{l}\text { Stationary wavelet entropy (SWE) + kernel } \\
\text { support vector machine trained by } \\
\text { biogeography-based optimization } \\
\text { (BBO-KSVM) (SWE + feed-forward neural } \\
\text { network trained by hybridized BBO and } \\
\text { particle swarm optimization (PSO)) }\end{array}$ & Higher than $97 \%$ & $\begin{array}{l}\text { The number of } \\
\text { features extracted } \\
\text { by these methods is } \\
\text { limited }\end{array}$ \\
\hline $\begin{array}{l}\text { Zhou } \\
(2016) \\
{[19]}\end{array}$ & $\begin{array}{c}\text { Wavelet entropy (WE) }+ \text { feed-forward neural } \\
\text { network }(\mathrm{FNN})\end{array}$ & $100 \%$ & $\begin{array}{c}\text { The used brain } \\
\text { images are only } 64\end{array}$ \\
\hline $\begin{array}{l}\text { Yang } \\
(2016) \\
{[28]}\end{array}$ & $\begin{array}{l}\text { Dual-tree complex wavelet transform } \\
\text { (DTCWT) +variance and entropy (VE) + } \\
\text { twin support vector machine (TSVM) }\end{array}$ & $99.57 \%$ & $\begin{array}{l}\text { Dataset cannot } \\
\text { reflect real-word } \\
\text { scenario }\end{array}$ \\
\hline $\begin{array}{c}\text { Yang } \\
(2017) \\
{[11]}\end{array}$ & $\begin{array}{l}\text { Hu moment invariants }(\mathrm{HMI})+\text { generalized } \\
\text { eigenvalue proximal support vector machine } \\
(\text { GEPSVM) }\end{array}$ & $98.89 \%$ & $\begin{array}{l}\text { The dataset only } \\
\text { consists of } 90 \\
\text { images }\end{array}$ \\
\hline $\begin{array}{l}\text { Chen } \\
(2017) \\
{[20]}\end{array}$ & $\begin{array}{l}\text { Wavelet packet Tsallis entropy (WPTE) + } \\
\text { feedforward neural network (FNN) }+ \\
\text { real-coded biogeography-based optimization } \\
\text { (RCBBO) }\end{array}$ & $99.49 \%$ & $\begin{array}{l}\text { The types of } \\
\text { pathological brain } \\
\text { are only } 8 \text {, and this } \\
\text { method is not } \\
\text { suitable for most } \\
\text { diseases }\end{array}$ \\
\hline $\begin{array}{c}\text { Wang } \\
(2016) \\
{[21]}\end{array}$ & $\begin{array}{c}\text { Wavelet entropy (WE) + multilayer } \\
\text { perception (MLP) + biogeography-based } \\
\text { optimization (BBO) }\end{array}$ & $\begin{array}{l}\text { Accuracy }=92.40 \%, \\
\text { sensitivity }=92.14 \%, \\
\text { specificity }=92.47 \%\end{array}$ & $\begin{array}{l}\text { Images from } \\
\text { dataset only consist } \\
\text { of } \mathrm{AD} \text { and } \mathrm{HC}\end{array}$ \\
\hline
\end{tabular}

\section{Conclusion and future works}

In this paper, we introduced many methods on pathological image detection, and these diseases include Alzheimer's disease, breast cancer, and hearing loss. We find that the accuracy of some methods reached to $100 \%$, which inspires us. Nevertheless, each method has its own scope of application.

After the analysis of these methods, we learned that multi-classification is on the stage of starting. It means we still need to learn more methods about multi-classification, so as to improve the accuracy of classification. In addition, due to small data set used in many proposed methods, we should select more representative and more images in future work. Some preprocessing methods [29, 30] should be discussed. 


\section{Acknowledgements}

This paper is supported by Open Program of Jiangsu Key Laboratory of 3D Printing Equipment and Manufacturing (3DL201602).

\section{References}

[1] Du, S., Alzheimer's Disease Detection by Pseudo Zernike Moment and Linear Regression Classification. CNS \& Neurological Disorders - Drug Targets, 2017. 16(1): pp. 11-15

[2] Liu, G., et al., Detection of Alzheimer's Disease by Three-Dimensional Displacement Field Estimation in Structural Magnetic Resonance Imaging. Journal of Alzheimer's Disease, 2016. 50(1): pp. 233-248

[3] Phillips, P., Three-Dimensional Eigenbrain for the Detection of Subjects and Brain Regions Related with Alzheimer's Disease. Journal Of Alzheimers Disease, 2016. 50(4): pp. 1163-1179

[4] Zhan, T.M. and Y. Chen, Multiple Sclerosis Detection Based on Biorthogonal Wavelet Transform, RBF Kernel Principal Component Analysis, and Logistic Regression. IEEE Access, 2016. 4: pp. 7567-7576

[5] Zhou, X.-X., Comparison of machine learning methods for stationary wavelet entropy-based multiple sclerosis detection: decision tree, k-nearest neighbors, and support vector machine. Simulation, 2016. 92(9): pp. 861-871

[6] Chen, Y. Voxelwise detection of cerebral microbleed in CADASIL patients by leaky rectified linear unit and early stopping: A class-imbalanced susceptibility-weighted imaging data study. Multimedia Tools and Applications, 2016, DOI: 10.1007/s11042-017-4383-9 (Online).

[7] Ghogomu, N., et al., Epidemiology of Unilateral Sensorineural Hearing Loss With Universal Newborn Hearing Screening. Laryngoscope, 2014. 124(1): pp. 295-300

[8] Zhan, T., Pathological brain detection by artificial intelligence in magnetic resonance imaging scanning. Progress in Electromagnetics Research, 2016. 156: pp. 105-133

[9] Wu, L., A hybrid method for MRI brain image classification. Expert Systems with Applications, 2011. 38(8): pp. 10049-10053

[10] Huo, Y. and L. Wu, Feature Extraction of Brain MRI by Stationary Wavelet Transform and its Applications. Journal of Biological Systems, 2010. 18(s): pp. 115-132

[11] Yang, J., Pathological brain detection in MRI scanning via $\mathrm{Hu}$ moment invariants and machine learning. Journal of Experimental \& Theoretical Artificial Intelligence, 2017. 29(2): pp. 299-312

[12] Grimm, L.J. and M.A. Mazurowski, A computer vision-based algorithm to predict false positive errors in radiology trainees when interpreting digital breast tomosynthesis cases. Expert Systems with Applications, 2016. 64: pp. 490-499

[13] Longman, C.F., et al., Imaging features and diagnosis of tuberculosis of the breast. Clinical Radiology, 2017. 72(3): pp. 217-222

[14] Vila, P.M. and J.E.C. Lieu, Asymmetric and unilateral hearing loss in children. Cell And Tissue Research, 2015. 361(1): pp. 271-278

[15] Chen, Y., A Feature-Free 30-Disease Pathological Brain Detection System by Linear Regression Classifier. CNS \& Neurological Disorders - Drug Targets, 2017. 16(1): pp. 5-10

[16] Sun, Y., A Multilayer Perceptron Based Smart Pathological Brain Detection System by Fractional Fourier Entropy. Journal of Medical Systems, 2016. 40(7), Article ID: 173

[17]Lu, Z., A Pathological Brain Detection System Based on Radial Basis Function Neural Network. Journal of Medical Imaging and Health Informatics, 2016. 6(5): pp. 1218-1222

[18] Atangana, A. Application of stationary wavelet entropy in pathological brain detection. Multimedia Tools and Applications, 2016, DOI: 10.1007/s11042-016-3401-7 (Online). 
[19]Zhou, X.X. and G.S. Zhang, Detection of abnormal MR brains based on wavelet entropy and feature selection. IEEJ Transactions on Electrical and Electronic Engineering, 2016. 11(3): pp. 364-373

[20]Chen, P. and S. Du, Pathological Brain Detection via Wavelet Packet Tsallis Entropy and Real-Coded Biogeography-based Optimization. Fundamenta Informaticae, 2017. 151: pp. 275-291

[21] Wang, S.-H. Single slice based detection for Alzheimer's disease via wavelet entropy and multilayer perceptron trained by biogeography-based optimization. Multimedia Tools and Applications, 2016, DOI: 10.1007/s11042-016-4222-4 (Online).

[22] Atem, F.D., et al., Linear regression with a randomly censored covariate: application to an Alzheimer's study. Journal Of the Royal Statistical Society Series C-Applied Statistics, 2017. 66(2): pp. 313-328

[23] Chen, Y., et al. Wavelet energy entropy and linear regression classifier for detecting abnormal breasts. Multimedia Tools and Applications, 2016, DOI: 10.1007/s11042-016-4161-0 (Online).

[24] Rao, R.V., et al., Abnormal Breast Detection in Mammogram Images by Feed-forward Neural Network trained by Jaya Algorithm. Fundamenta Informaticae, 2017. 151: pp. 191-211

[25] Li, J., Detection of Left-Sided and Right-Sided Hearing Loss via Fractional Fourier Transform. Entropy, 2016. 18(5), Article ID: 194

[26] Nayak, D.R. Detection of unilateral hearing loss by Stationary Wavelet Entropy. CNS \& Neurological Disorders - Drug Targets, 2017. 16, DOI: 10.2174/1871527315666161026115046 (Online).

[27] Gorriz, J.M. and J. Ramírez, Wavelet entropy and directed acyclic graph support vector machine for detection of patients with unilateral hearing loss in MRI scanning. Frontiers in Computational Neuroscience, 2016. 10, Article ID: 160

[28] Yang, M., Dual-Tree Complex Wavelet Transform and Twin Support Vector Machine for Pathological Brain Detection. Applied Sciences, 2016. 6(6), Article ID: 169

[29] Wu, L.N., Improved image filter based on SPCNN. Science In China Series F-Information Sciences, 2008. 51(12): pp. 2115-2125

[30] Wu, L.N., Segment-based coding of color images. Science in China Series F-Information Sciences, 2009. 52(6): pp. 914-925 